\title{
Changes on Texture and Crystalline Phase of Activated Carbon-Supported Ni-Ca Catalyst During Dry Methane Reforming
}

\author{
Juan Matos ${ }^{*}, 1$, Maibelin Rosales ${ }^{1}$, Gema González ${ }^{1}$ and Caribay Urbina de Navarro ${ }^{2}$ \\ ${ }^{I}$ Engineering of Materials and Nanotechnology Centre, Venezuelan Institute for Scientific Research, I.V.I.C., 20632, \\ Caracas 1020-A, Venezuela \\ ${ }^{2}$ Centre for Electron Microscopy, Central University of Venezuela, Caracas 1040, Venezuela
}

\begin{abstract}
Changes on texture and crystalline phase of AC-supported Ni-Ca catalyst during dry methane reforming were verified. Characterization by $\mathrm{N}_{2}$ adsorption, XPS, XRD, TEM and HR-TEM was performed. XPS and XRD analysis suggest that the initial activity can be attributed to a nickel reduced phase formed during helium pre-treatment. TEM showed that a homogeneous distribution of Ni nanoparticles between 10-20nm at the tip of multi-walled carbon nanotubes is formed during reaction. HR-TEM showed diffusion of Ni nanoparticles and the formation of carbon-like nano onions with an interlayer separation of $0.5 \mathrm{~nm}$ suggesting the formation of a ultra-microporous carbon structure. An increase in surface area from $231 \mathrm{~m}^{2} . \mathrm{g}^{-1}$ to $2405 \mathrm{~m}^{2} . \mathrm{g}^{-1}$ after $90 \mathrm{~min}$ reaction was found and attributed to an in situ activation of carbon deposits by $\mathrm{CO}_{2}$ gasification. The present results suggest that introducing $\mathrm{CO}_{2}$ pulses during reaction carbon-supported $\mathrm{Ni}-\mathrm{Ca}$ could be employed as potential catalysts for methane and other hydrocarbon reforming reactions at mild experimental conditions.
\end{abstract}

Keywords: Activation, Carbon deposits, Dry methane reforming, Ni-based catalyst.

\section{INTRODUCTION}

In the following years is expected an increasing production and conversion of methane because it is the main component of natural gas. Methane can be transformed to syngas by reforming and this mixture of $\mathrm{CO}$ and $\mathrm{H}_{2}$ can be employed to obtain different upgrading molecules as green diesel, methanol and dimethyl ether. Though the supported noble metals catalysts showed the highest activity for methane conversion reactions [1-3] an economic alternative are nickel-based catalysts [4-7]. The industrial development of Ni-based catalysts in dry methane reforming is not well established due to its poor stability, mainly by high coking rates and consequent deactivation phenomena [2,4]. In addition, activity and stability of Ni-based catalysts for methane conversion reactions depend on texture and surface properties of supports [6,7]. Activated carbon (AC) presents several advantages such as low cost, control of texture and surface chemistry during synthesis, high thermal conductivity, easy recovery of active phase from deactivated catalysts and so on $[8,9]$ to be employed as catalytic support. However, activated carbon is not a common catalytic support for methane reforming reactions [10] because it can suffer gasification by steam or by $\mathrm{CO}_{2}$. Both reactions are spontaneous at about $700^{\circ} \mathrm{C}$ but in a preliminary study of dry methane reforming on a carbon-supported $\mathrm{Ni}-\mathrm{Ca}$ catalyst [11] we showed $\mathrm{CO}_{2}$ can help control excess of carbon deposits without any detrimental effect on carbon supports after $5 \mathrm{~h}$ reaction at $650^{\circ} \mathrm{C}$. It was also reported [11] that

*Address correspondence to this author at the Engineering of Materials and Nanotechnology Centre, Venezuelan Institute for Scientific Research, I.V.I.C., 20632, Caracas 1020-A, Venezuela; Tel/Fax: +58-212-5041922;

E-mail: jmatos@ivic.gob.ve
$\mathrm{NiCa} / \mathrm{AC}$ catalyst pre-treated under helium flow at temperatures from 550 up to $800^{\circ} \mathrm{C}$ showed higher methane conversions than those obtained after pre-treatment under $\mathrm{H}_{2}$ flow. However, contrary to our preliminary work [11], Chen and co-workers [7] reported that in absence of carbon dioxide or steam an activated carbon-supported nickel-based catalyst was deactivated by $\mathrm{Ni}_{3} \mathrm{C}$ formed during methane decomposition. $\mathrm{Li}$ and co-workers [12] found that the catalytic activity of pure $\mathrm{Ni}$ catalyst for methane decomposition was related to the crystalline size of reduced $\mathrm{Ni}$. They pointed out that during reaction $\mathrm{Ni}$ particles suffered important changes. They suggested that carbon deposits in the shape of carbon nanofilaments affect both size and morphology of metallic nickel crystals and these same authors [13] found that the diameter of carbon filaments is controlled by the size of catalyst particles. The objective of this work is to study the changes on texture and crystalline phase of AC-supported $\mathrm{Ni}$-Ca catalyst during dry methane reforming at mild experimental conditions and to correlate these changes with activity and stability of catalyst.

\section{EXPERIMENTAL}

$\mathrm{Ni}(5 \mathrm{wt} \%)-\mathrm{Ca}(1 \mathrm{wt} \%)$ catalyst was prepared by incipient wetness impregnation with nickel and calcium nitrate solutions on a commercial activated carbon (AC) purchased from Merck [Langmuir surface area $907 \mathrm{~m}^{2} \mathrm{~g}^{-1}, 22 \AA$ mean pore width, ash content $<1 \mathrm{wt} \%]$ following the procedure described in previous works $[10,11]$. Impregnation order is given by the sequence of elements, i.e., Ni followed by $\mathrm{Ca}$. This catalyst was chosen because in a previous study [10] it showed the best activity for dry methane reforming. Characterization by $\mathrm{N}_{2}$ adsorption-desorption isotherms, Xray photoelectron spectroscopy (XPS), X-ray diffraction (XRD) and transmission electron microscopy (TEM, HR- 
TEM) was performed. $\mathrm{N}_{2}$ adsorption-desorption isotherms permit to verify the changes in textural properties of the catalysts. XPS spectra permit to verify mainly the change in electronic states of nickel and its interaction with carbon support. XRD patterns permit to verify the changes in crystalline phases of nickel species and the presence of metallic carbides crystallites. TEM studies permit to verify the changes in morphology and topology of the catalyst. Exsitu XPS was carried out in an ESCALAB 220i-XL spectrometer (VG Scientific) equipped with a hemispherical electron analyzer and a double anode Mg-Al nonmonochromatic X-ray source. The pressure in the analysis chamber was kept below $10^{-9}$ Torr. Samples were protected from exposition to the atmosphere by immersion into an ultra-dry hydrocarbon solvent (purified heptanes) while transferring from the reactor to the chamber of the spectrometer. Texture characterization was performed by $\mathrm{N}_{2}$ adsorption-desorption isotherms at $77 \mathrm{~K}$. The full isotherms in the range of $4 \times 10^{-3}$ to $84 \mathrm{kPa}$ were measured in a Micromeritics ASAP-2010. Surface area, micropore area, pore volume and pore diameters were obtained by Langmuir isotherms, t-plot method and Harkins-Jura [14] method, respectively. These methods were employed because they permit an accounting for the adsorbed layer on pore walls, when calculating pore size distribution, and they are very useful when different types of pores are involved. Langmuir isotherm and Harkins-Jura method are appropriate for the present case because samples contain slits and spherical pores. Powder X-ray diffraction (XRD) patterns were recorded in the range of $2 \theta=10-80^{\circ}$ on a D-5005 diffractometer from Siemens with $\mathrm{Cu} \mathrm{K} \alpha$ (1.54056) radiation and processed with the Diffrac-Plus-Eva program. A transmission electron microscope (TEM) operating at $100 \mathrm{keV}$ accelerating voltage was used for the microscopy study. TEM samples were prepared from ethanol suspensions and placed on copper grids. HR-TEM was performed in a TECNAI ST G-20 equipment operating at $200 \mathrm{keV}$. Catalyst's samples were in situ pre-treated under helium flow $\left(50 \mathrm{~cm}^{3} \cdot \mathrm{min}^{-1}, 100 \mathrm{kPa}\right.$ pressure $)$ at $650^{\circ} \mathrm{C}$ with a heating rate of $10^{\circ} \mathrm{C} / \mathrm{min}$ before reaction. Catalytic activity was followed in a continuous flow system (quartz reactor) flowing both reactants $\left(\mathrm{CH}_{4}\right.$ and $\left.\mathrm{CO}_{2}\right)$ at nearly atmospheric pressure $(100 \mathrm{kPa})$. Analysis of $\mathrm{CH}_{4}$ was carried out with gas chromatography (Varian $3700 \mathrm{GC}$ apparatus) with a flame ionization detector (FID) and employing a Porapak R packed column at $50^{\circ} \mathrm{C}$. Catalytic activity was reported as mmols methane converted by time and catalysts weight. Reaction conditions were the following: $150 \mathrm{mg}$ catalyst sample, $80 \mathrm{~cm}^{3} \cdot \mathrm{min}^{-1}$ flow of $\mathrm{CH}_{4}$ and $\mathrm{CO}_{2}(50 \mathrm{vol} \%$ each reactant), and reaction temperature $650^{\circ} \mathrm{C}$ (similar to that of the pretreatment). Activity tests were done in triplicate and the reproducibility was better than $5 \%$.

\section{RESULTS AND DISCUSSION}

\subsection{Methane Conversion and XPS Analysis}

Fig. (1) shows the catalytic activity of $\mathrm{Ni} / \mathrm{AC}$ and $\mathrm{Ni}-$ $\mathrm{Ca} / \mathrm{AC}$. Initial activities are very similar with 11.7 and $10.3 \mathrm{mmols} \mathrm{min}^{-1} \cdot \mathrm{g}_{\mathrm{cat}}{ }^{-1}$ for Ni/AC (Fig. 1A) and Ni-Ca/AC (Fig. 1B), respectively. Activities decreased to 4.2 and $7.7 \mathrm{mmols} \cdot \mathrm{min}^{-1} \cdot \mathrm{g}_{\mathrm{cat}}{ }^{-1}$ after $4 \mathrm{~h}$ reaction and to 1.2 and $3.2 \mathrm{mmols} \cdot \mathrm{min}^{-1} \cdot \mathrm{g}_{\mathrm{cat}}{ }^{-1}$ after $24 \mathrm{~h}$ reaction. This is a deactivation of $90 \%$ and $70 \%$ relative to initial activities for
$\mathrm{Ni} / \mathrm{AC}$ and $\mathrm{Ni}-\mathrm{Ca} / \mathrm{AC}$, respectively. In a previous work [10], we showed that catalytic activity of $\mathrm{Ca} / \mathrm{AC}$ is negligible [10]. Therefore the present results suggest that calcium, in the form of $\mathrm{CaO}$ or $\mathrm{CaCO}_{3}$ [10], would play a promoter role in the present bimetallic system, as has been earlier reported $[3,6]$.
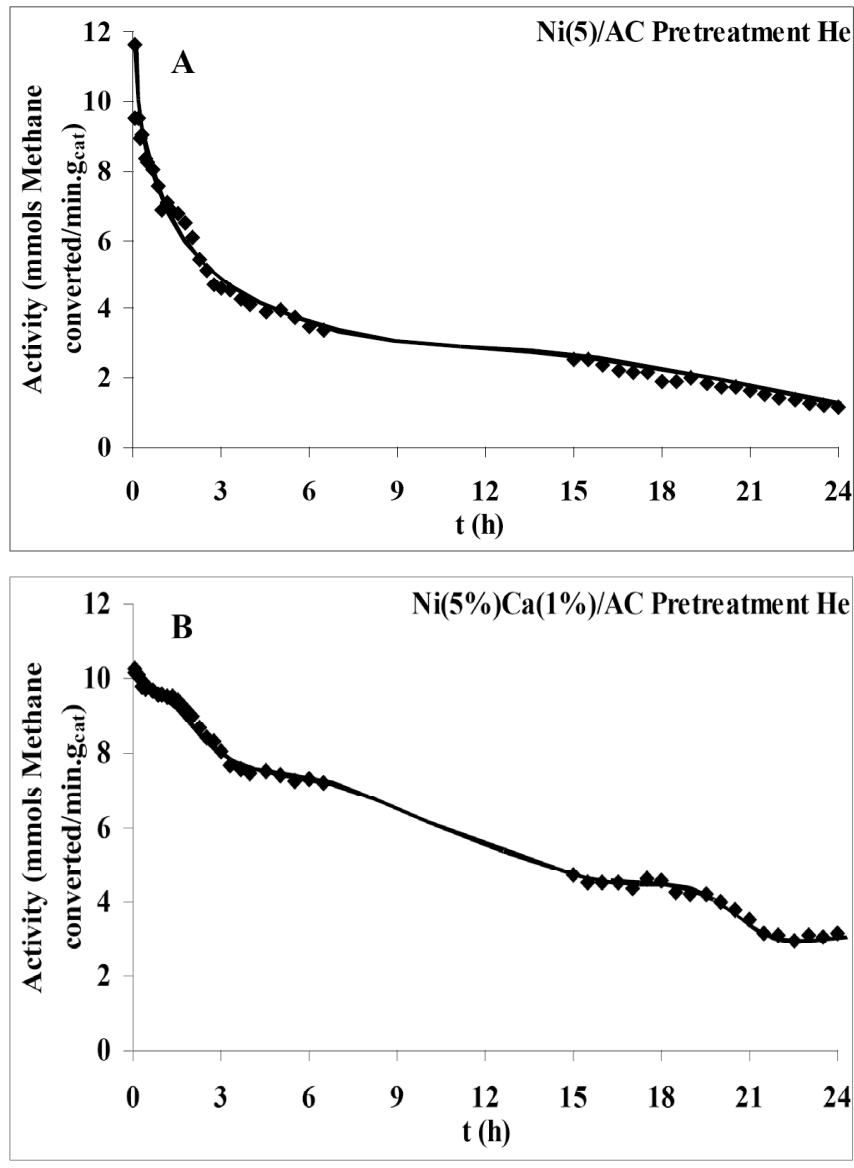

Fig. (1). Catalytic activity after $\mathrm{He}$ pretreatment at $650^{\circ} \mathrm{C}$ by $1 \mathrm{~h}$. (A): Ni/AC. (B): Ni-Ca/AC.

Activity of Ni-based catalysts can be explained from changes in $\mathrm{Ni}^{+2}$ binding energies detected in $\mathrm{Ni} 2 \mathrm{p}$ region from XPS. It can be seen from Fig. (2) that in comparison to the crude catalyst the binding energy of nickel in Ni-Ca/AC decreased about $2 \mathrm{eV}$ (from $855.8 \mathrm{eV}$ to $853.9 \mathrm{eV}$ ) after $\mathrm{He}$ pre-treatment. By contrast, we showed [10] that in absence of calcium, the binding energy of $\mathrm{Ni}^{+2}$, for $\mathrm{Ni} / \mathrm{AC}$, only decreased in about $0.9 \mathrm{eV}$ after He pre-treatment. The role of electron donors of $\mathrm{CaO}$ and $\mathrm{CaCO}_{3}$ is well-known [15] and the present result suggest that calcium phases would induce an easier reduction of $\mathrm{Ni}^{+2}$ to lower oxidation states, probably by its interaction with carbon atoms from support [8]. However, the peak found for the binding energy of nickel $(853.9 \mathrm{eV})$ in $\mathrm{Ni}-\mathrm{Ca} / \mathrm{AC}$ catalyst after He pretreatment does not correspond to a full reduction to elemental nickel since the binding energy of $\mathrm{Ni}^{0}$ is about $852 \mathrm{eV}$. It can be inferred from XPS results (Fig. 2), that a Ni phase richer in electron density was formed during pre-treatment, probably a mixture of elemental nickel and nickel carbide phases, in the form of $\mathrm{NiC}$ or $\mathrm{Ni}_{3} \mathrm{C}$. These metallic carbide phases can be deduced from XPS spectra of $\mathrm{C} 1 \mathrm{~s}$ region (Fig. 3). Fig. (3A, B) present the Gaussian analysis of carbon main peak after He pre-treatment at $650^{\circ} \mathrm{C}$ by $1 \mathrm{~h}$ and after $90 \mathrm{~min}$ reaction, 
respectively. After helium pretreatment, besides a signal about $286.4 \mathrm{eV}$ attributed to cyclic ether groups (-C-O-C-) on the surface of activated carbons [11], another signal about $283.9 \mathrm{eV}$ was also detected (Fig. 3A). This signal has been attributed by Mirodatos and co-workers [16] to a nickel carbide phase $\mathrm{Ni}_{3} \mathrm{C}$. These authors showed that nickel carbide-like layers are formed in the initial period of reaction of dry methane reforming. After 90min reaction (Fig. 3B) the intensity of this signal increase and another signal is also detected about $282.6 \mathrm{eV}$ and attributed to carbon filaments [16]. We propose, in agreement with Mirodatos [16] that a mixture of reduced nickel and $\mathrm{Ni}_{3} \mathrm{C}$ are responsible for the initial conversion of methane on $\mathrm{Ni}-\mathrm{Ca} / \mathrm{AC}$ catalyst.

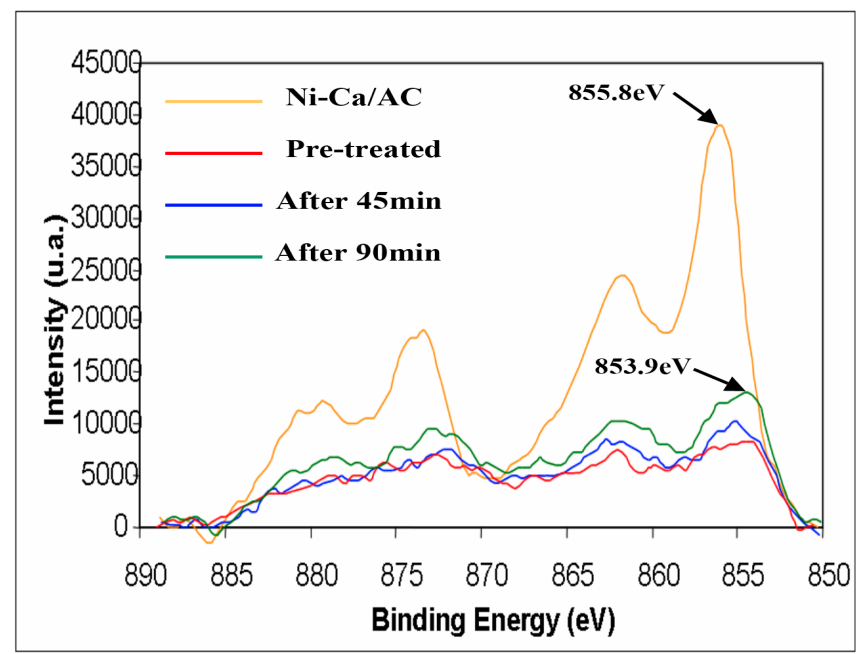

Fig. (2). Changes in XPS spectra in $\mathrm{Ni} 2 \mathrm{p}$ region $\mathrm{Ni}-\mathrm{Ca} / \mathrm{AC}$ catalyst.

\subsection{Texture and Crystalline Phase Characterization}

$\mathrm{N}_{2}$ adsorption-desorption isotherms for $\mathrm{AC}$ and $\mathrm{Ni}$ $\mathrm{Ca} / \mathrm{AC}$ catalyst before and after He pretreatment are shown in Fig. (4) while Fig. (5) shows the $\mathrm{N}_{2}$ adsorption-desorption isotherms of $\mathrm{Ni}-\mathrm{Ca} / \mathrm{AC}$ catalyst after $45 \mathrm{~min}$ and $90 \mathrm{~min}$ reaction. We have chosen these reaction times to characterize the changes in textural properties because in a previous work about ethylene hydrogenation reaction [9] we found that the most important changes on the catalytic activity of $\mathrm{Ni}$ $\mathrm{Mo} / \mathrm{AC}$ and on nickel crystalline phases occurred during the first 90min reaction. All isotherms in Figs. (4, 5) showed a micro- and mesopores framework and they seem to be an IVtype adsorption isotherms by the hysteresis loop observed. A summary of Langmuir surface area, micropore area, pore volume and mean pore diameters is shown in Table 1. Ni$\mathrm{Ca} / \mathrm{AC}$ catalyst showed an increase in surface area from $231 \mathrm{~m}^{2} \cdot \mathrm{g}^{-1}$ (after pretreatment) up to $2405 \mathrm{~m}^{2} \cdot \mathrm{g}^{-1}$ after $90 \mathrm{~min}$ reaction. This increase can be attributed to a higher proportion of microporous framework suggested by the enhancement in micropore volume $\left(0.841 \mathrm{~cm}^{3} \cdot \mathrm{g}^{-1}\right.$ against $\left.0.068 \mathrm{~cm}^{3} \cdot \mathrm{g}^{-1}\right)$. Surface area and micropore volume of $\mathrm{Ni}$ $\mathrm{Ca} / \mathrm{AC}$ after $90 \mathrm{~min}$ reaction are clearly higher than those obtained for the AC alone $\left(2405 \mathrm{~m}^{2} \cdot \mathrm{g}^{-1}\right.$ and $0.841 \mathrm{~cm}^{3} \cdot \mathrm{g}^{-1}$ against $907 \mathrm{~m}^{2} \cdot \mathrm{g}^{-1}$ and $\left.0.268 \mathrm{~cm}^{3} \cdot \mathrm{g}^{-1}\right)$. Therefore, we suggest that carbon deposits formed during reaction clearly affects the global texture of $\mathrm{Ni}-\mathrm{Ca} / \mathrm{AC}$ catalyst. Carbon deposits would be produced primary, from methane disproportion $\left(\mathrm{CH}_{4} \rightarrow \mathrm{C}+2 \mathrm{H}_{2}\right)$. In addition, since $\mathrm{CO}$ is one product
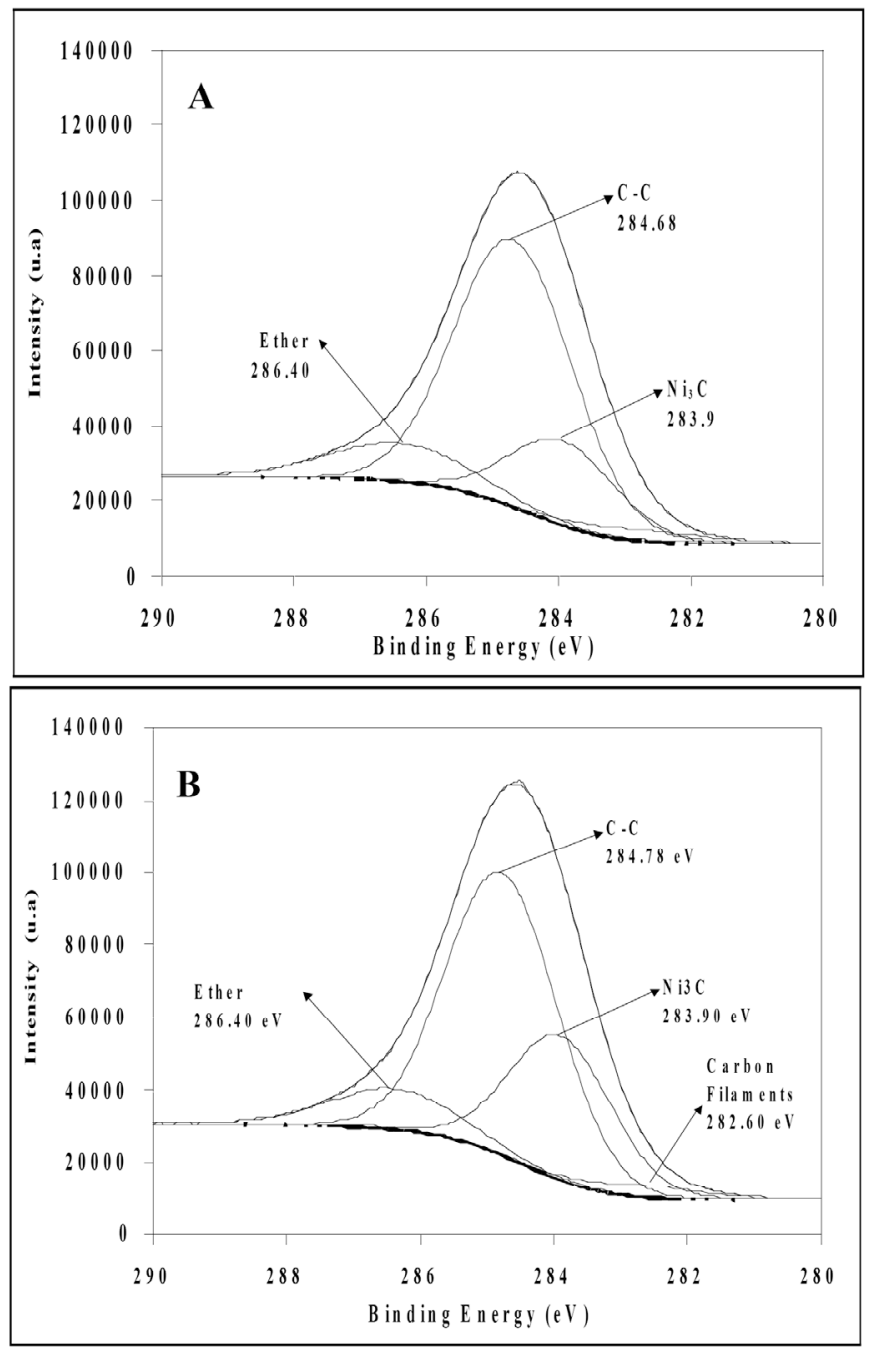

Fig. (3). XPS spectra in $\mathrm{C} 1 \mathrm{~s}$ region for $\mathrm{Ni}-\mathrm{Ca} / \mathrm{AC}$. (A): After $\mathrm{He}$ pre-treatment at $650^{\circ} \mathrm{C}, 1 \mathrm{~h}$. (B): After $90 \mathrm{~min}$ reaction at $650^{\circ} \mathrm{C}$.

reaction, carbon nanotubes could be formed from carbon monoxide disproportion [17]. However, carbon nanotubes are typical mesoporous materials with a relatively low surface area between $100 \mathrm{~m}^{2} \cdot \mathrm{g}^{-1}$ up to $250 \mathrm{~m}^{2} \cdot \mathrm{g}^{-1}$ [17]. Therefore, is neither possible that an increase in one order magnitude in the surface area in the present work can be due to carbon nanotubes nor to the clean of the internal surface of activated carbon because its surface area is about $907 \mathrm{~m}^{2} . \mathrm{g}$ 1 which is clearly lower than $2405 \mathrm{~m}^{2} \cdot \mathrm{g}^{-1}$. Therefore, to explain the present results we suggest an in situ activation of carbon deposits by gasification with $\mathrm{CO}_{2}$ according to the reversal Boudouart reaction $\left(\mathrm{C}+\mathrm{CO}_{2} \rightarrow 2 \mathrm{CO}\right)[18,19]$. The overall reaction pathway would involve the adsorption and cracking of methane and $\mathrm{CO}_{2}$ adsorption to react with carbon deposits as suggested by Xiao et al. [20]. The present results are also in agreement with Laine et al. [21] whom reported the addition of a micropore framework to a parent $\mathrm{Ni}$ supported activated carbon catalyst by carbon deposits formed from methane and ethylene decomposition.

XRD patterns (Fig. 6) of $\mathrm{Ni}-\mathrm{Ca} / \mathrm{AC}$ catalyst show the characteristic (012) plane of $\mathrm{NiO}$ phase at $2 \theta=43.3^{\circ}$ in the non pretreated catalyst (Fig. 6A). This phase is also observed after pre-treatment (Fig. 6B), after 45min (Fig. 6C) and 

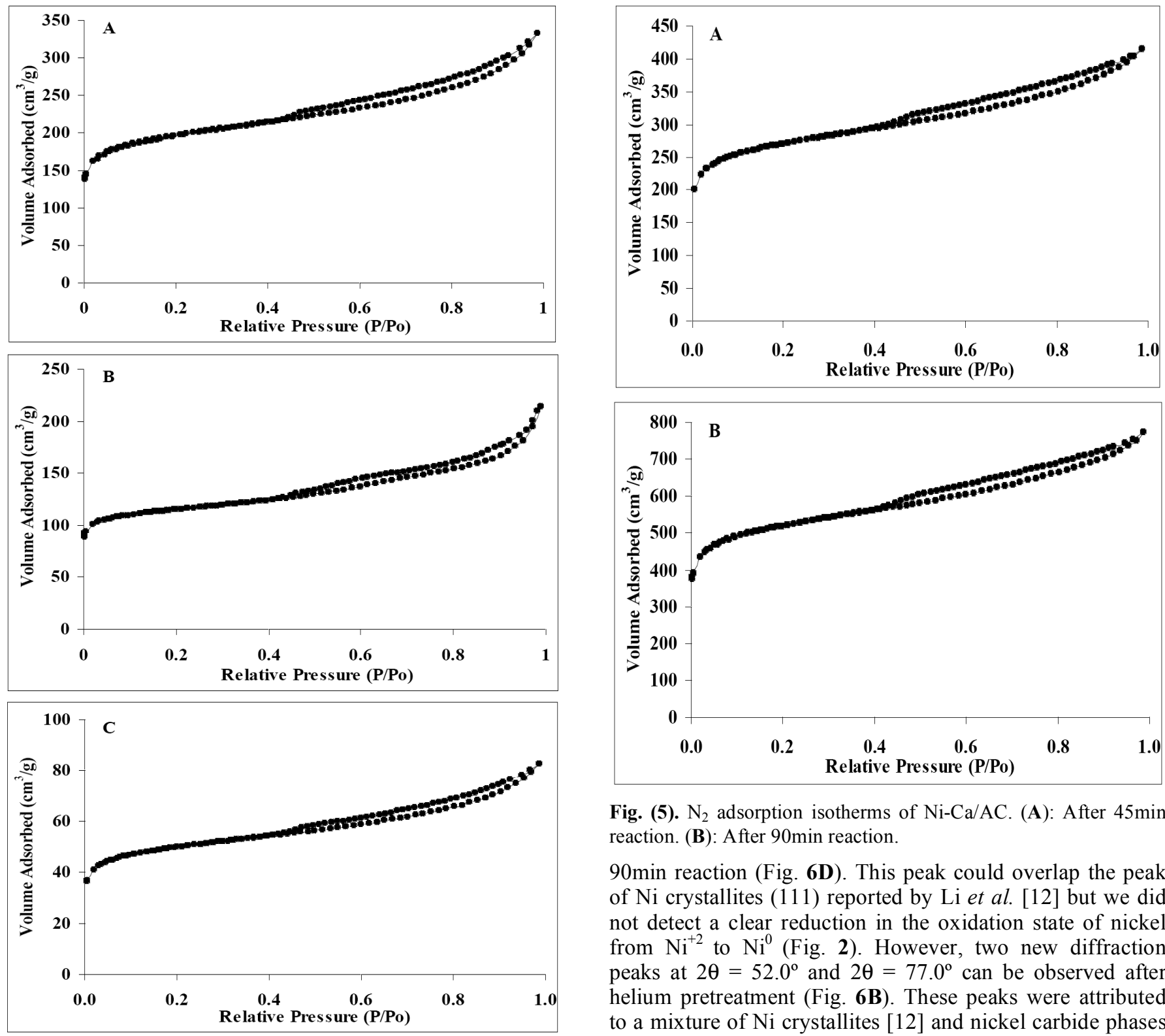

Fig. (4). $\mathrm{N}_{2}$ adsorption isotherms. (A): $\mathrm{AC},(\mathbf{B})$ : $\mathrm{Ni}-\mathrm{Ca} / \mathrm{AC},(\mathbf{C})$ : $\mathrm{Ni}-$ $\mathrm{Ca} / \mathrm{AC}$ after pretreatment under $\mathrm{He}, 650^{\circ} \mathrm{C}$ by $1 \mathrm{~h}$.

Fig. (5). $\mathrm{N}_{2}$ adsorption isotherms of $\mathrm{Ni}-\mathrm{Ca} / \mathrm{AC}$. (A): After $45 \mathrm{~min}$ reaction. (B): After $90 \mathrm{~min}$ reaction.

90min reaction (Fig. 6D). This peak could overlap the peak of $\mathrm{Ni}$ crystallites (111) reported by Li et al. [12] but we did not detect a clear reduction in the oxidation state of nickel from $\mathrm{Ni}^{+2}$ to $\mathrm{Ni}^{0}$ (Fig. 2). However, two new diffraction peaks at $2 \theta=52.0^{\circ}$ and $2 \theta=77.0^{\circ}$ can be observed after helium pretreatment (Fig. 6B). These peaks were attributed to a mixture of $\mathrm{Ni}$ crystallites [12] and nickel carbide phases $\mathrm{NiC}$ and $\mathrm{Ni}_{3} \mathrm{C}$. The formation of these crystalline phases from the interaction of $\mathrm{NiO}$ with activated carbon has been

Table 1. Summary of Textural Properties in $\mathrm{AC}$ and $\mathrm{Ni}-\mathrm{Ca} / \mathrm{AC}$

\begin{tabular}{|c|c|c|c|c|c|}
\hline Textural Properties & AC & $\mathrm{Ni}-\mathrm{Ca} / \mathrm{AC}$ & After He Pretreatment & After 45min Reaction & After 90min Reaction \\
\hline $\mathrm{S}_{\text {Langmuir }}\left(\mathrm{m}^{2} / \mathrm{g}\right)$ & 907 & 529 & 231 & 1269 & 2405 \\
\hline Microporous proportion (\%) & 86 & 86 & 87 & 91 & 92 \\
\hline Total pore volume $\left(\mathrm{cm}^{3} / \mathrm{g}\right)^{\mathrm{c}}$ & 0.515 & 0.331 & 0.128 & 0.642 & 1.198 \\
\hline Meso/macropore volume $\left(\mathrm{cm}^{3} / \mathrm{g}\right)^{\mathrm{d}}$ & 0.331 & 0.211 & 0.081 & 0.0381 & 0.674 \\
\hline Mean pore diameters $(\AA)^{\mathrm{e}}$ & 22.7 & 25.0 & 22.1 & 20.2 & 19.9 \\
\hline
\end{tabular}

${ }^{b}$ Microporous proportion $(\%)=($ microporous area/Langmuir surface area $) .100$.

${ }^{c}$ Pore diameters less than $1489.0816 \AA$ at $\mathrm{P} / \mathrm{P}_{0}$ equal to 0.98683317 .

${ }^{\mathrm{d}}$ For pore diameters between $17 \AA$ and $3000 \AA$.

'Obtained from Harkins-Jura method [14]. 


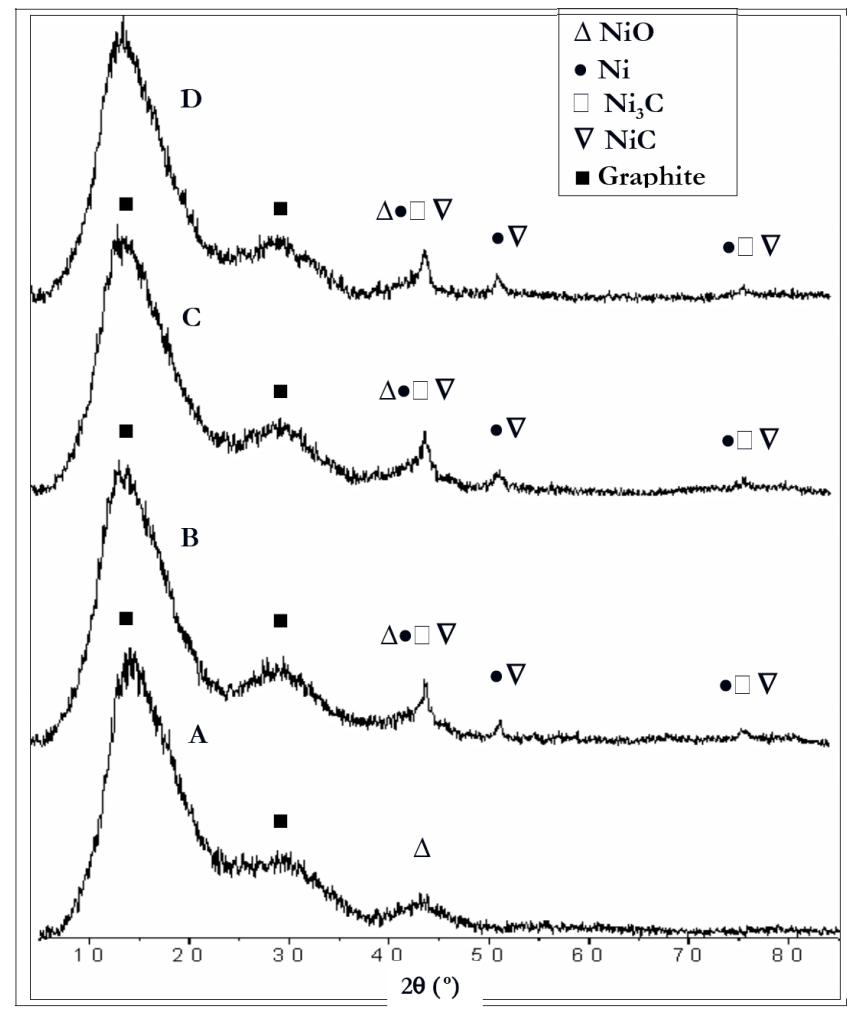

Fig. (6). XRD patterns of Ni-Ca/AC catalyst. (A): No treatment. (B): After He pre-treatment. (C): After $45 \mathrm{~min}$ reaction. (D): After 90 min reaction.

already reported by our group [8] in a work related with ethylene hydrogenation on Ni-Mo/AC catalyst. The formation of nickel carbide in the $\mathrm{Ni}-\mathrm{Ca} / \mathrm{AC}$ catalyst can be explained taking into account that $\mathrm{Ca}$ atomic radius is larger than that of $\mathrm{Ni}(2.35 v s 1.24 \AA)$, then nickel particles would diffuse easier through AC micropore framework to the external surface, and once there these nickel atoms would react with carbon atoms from support or from carbon deposits formed during reaction. This interaction between $\mathrm{NiO}$ and $\mathrm{C}$ atoms leads to elemental nickel and nickel carbide crystallites, in agreement with results reported by Bai et al. [7]. As expected, $\mathrm{CaO}$ diffraction peaks were not detected in XRD patterns because the calcium composition in catalyst is only of about $1 \mathrm{wt} \%$, and therefore it is diluted by the AC support. A comparison between the percentages in weight of elements constituting $\mathrm{Ni}-\mathrm{Ca} / \mathrm{AC}$ catalyst is compiled in Table 2. It can be seen that $\mathrm{Ni} / \mathrm{C}$ atom rate decrease from 0.092 to 0.029 for non-pretreated and pretreated catalyst, respectively and this value remains practically constant after 45 and $90 \mathrm{~min}$ reaction. These results suggest that the interaction between $\mathrm{Ni}$-catalyst and carbon could occur not only with carbon atoms from support but also from carbon atoms from carbonaceous deposits leading to a dynamic formation of $\mathrm{Ni}_{3} \mathrm{C}$ along the reaction. It should be considered that though $\mathrm{Ni}_{3} \mathrm{C}$ can be formed at low temperatures it is not thermodynamically stable at high temperatures and therefore it is expected to decompose into $\mathrm{C}$ and Ni. A more detailed XRD and in-situ XPS studies would be necessary to come to a conclusion of the real influence of $\mathrm{Ni}_{3} \mathrm{C}$ phase on catalytic activity of $\mathrm{Ni}-\mathrm{Ca} / \mathrm{AC}$.

\subsection{Carbon Deposits and Morphology}

Fig. (7) shows a TEM image of Ni-Ca/AC catalyst pretreated under $\mathrm{He}$ flow at $650^{\circ} \mathrm{C}$ for $1 \mathrm{~h}$. A metallic phase with different sizes on AC surface (indicated with black arrows and white circles) can be observed. TEM image from Fig. (8) shows a clear change in the morphology of catalyst with the appearance of carbon nanofibers with external diameters of about $30 \mathrm{~nm}$. These fibers consist of curved and hollow multi-walled carbon nanotubes (MW-CNT) with an internal diameter around 7-10nm. Also in Fig. (8), nanoparticles of different sizes inside and at the CNTs tips were detected. These particles would be mainly composed by different nickel crystallites phases, as discussed above from XPS and XRD studies. Comparison of TEM images in Figs. $(\mathbf{7}, \mathbf{8})$ suggest that crystallites diffused from the external surface of AC (Fig. 7) along CNT (Fig. 8). After 90min reaction, TEM image (Fig. 9) showed that crystallites change into a homogeneous distribution of Ni nanoparticles between 10$20 \mathrm{~nm}$ sizes. In agreement with the acceptable stability of $\mathrm{Ni}$ $\mathrm{Ca} / \mathrm{AC}$ catalyst which suffered a decrease in activity of about $70 \%$ after $24 \mathrm{~h}$ reaction relative to the initial activity (Fig. 1), this highly dispersed $\mathrm{Ni}$ nanoparticles distribution would inhibit sintering of catalyst. This distribution could be formed from the fragmentation of nickel particles along the filament growth, with the concomitant formation of smaller crystallites. This fragmentation has been attributed to the appearance of various forces influenced by the specific physical and chemical properties of the support [21,22]. Finally, a HR-TEM study was carried out for the Ni-Ca/AC catalyst after $90 \mathrm{~min}$ reaction. Nanoparticles (white arrows) with diameters from $5 \mathrm{~nm}$ (Fig. 10A) to $10 \mathrm{~nm}$ (Fig. 10B) were detected after this reaction time. It should be pointed out the apparent diffusion of crystallites (Fig. 10C) through several very-well aligned (white arrow) carbon layers. It can be seen from Fig. (10C) that about 10 graphene parallel

Table 2. Changes in Atomic Weights (At \%) of Elements Detected in Ni-Ca/AC Catalyst from the Corresponding Regions Analyzed by XPS

\begin{tabular}{|c|c|c|c|c|c|c|}
\hline Sample & $\mathbf{N i}$ & $\mathbf{O}$ & $\mathbf{C a}$ & $\mathbf{C}$ & $\mathbf{N i / C}$ & $\mathbf{C a} / \mathbf{C}$ \\
\hline \hline AC & $-\ldots$ & 8.505 & $-\ldots$ & 91.495 & $-\ldots$ & $-\ldots$ \\
\hline Ni-Ca/AC non pre-treated & 7.136 & 14.619 & 0.407 & 77.838 & 0.092 & 0.0052 \\
\hline Ni-Ca/AC after pre-treatment & 2.724 & 1.528 & 0.311 & 95.436 & 0.029 & 0.0033 \\
\hline Ni-Ca/AC after 45min reaction & 2.261 & 4.130 & 0.326 & 93.264 & 0.024 & 0.0035 \\
\hline Ni-Ca/AC after 90min reaction & 2.757 & 5.314 & 0.330 & 91.599 & 0.030 & 0.0036 \\
\hline
\end{tabular}




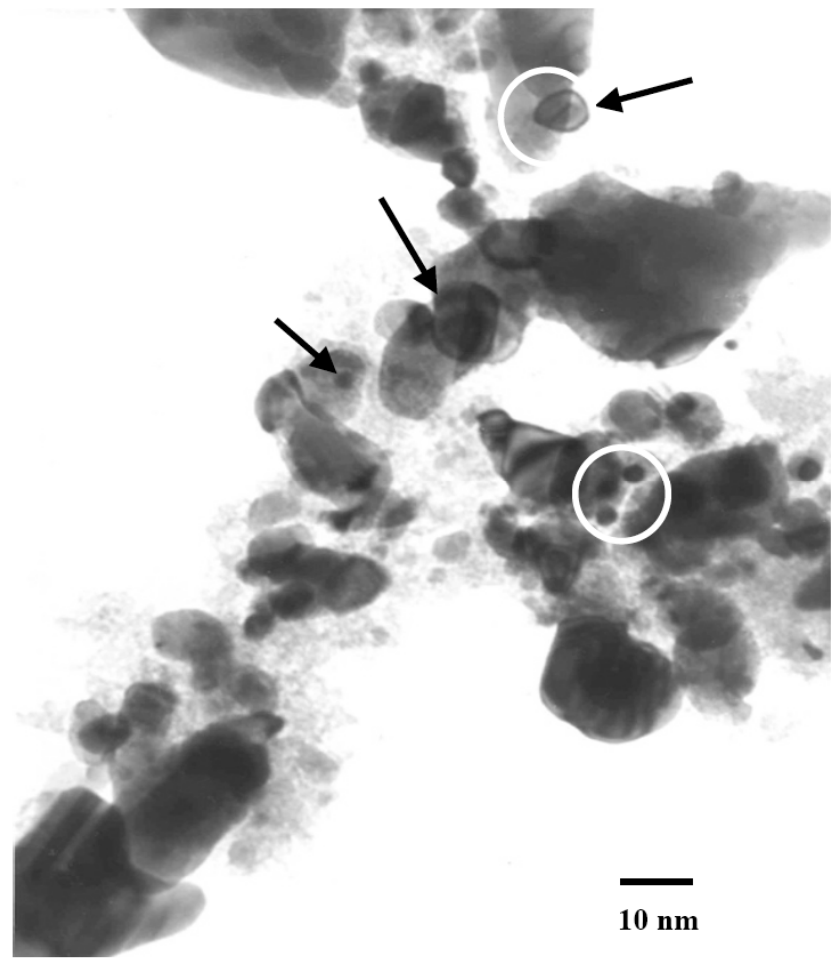

Fig. (7). TEM image of $\mathrm{Ni}-\mathrm{Ca} / \mathrm{AC}$ after $\mathrm{He}$ pre-treatment at $650^{\circ} \mathrm{C}$, $1 \mathrm{~h}$.

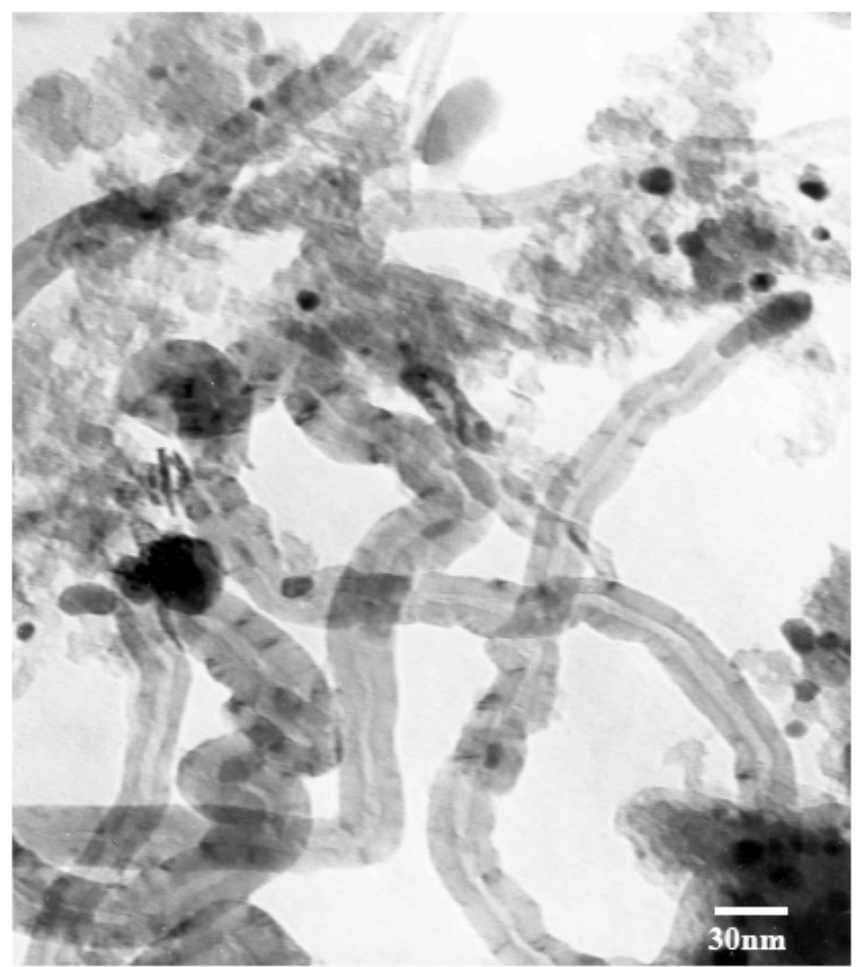

Fig. (8). TEM image of $\mathrm{Ni}-\mathrm{Ca} / \mathrm{AC}$ After $45 \mathrm{~min}$ reaction at $650^{\circ} \mathrm{C}$.

layers correspond to a separation of $0.5 \mathrm{~nm} /$ layer. This value is slightly higher than pristine graphite $(0.334 \mathrm{~nm})$, suggesting that the present carbon deposits would correspond to the specific case of a supermicroporous $\mathrm{AC}$ $[23,24]$. This feature is in fully agreement with the increase in surface area observed in $\mathrm{Ni}-\mathrm{Ca} / \mathrm{AC}$ (Table 1) that we suggest as the consequence of an in situ activation by $\mathrm{CO}_{2}$ of carbon deposits formed during reaction. In addition, HRTEM image from Fig. (10D) showed that this carbon composite have the apparent morphology of carbon nano onions (white circle) [25].

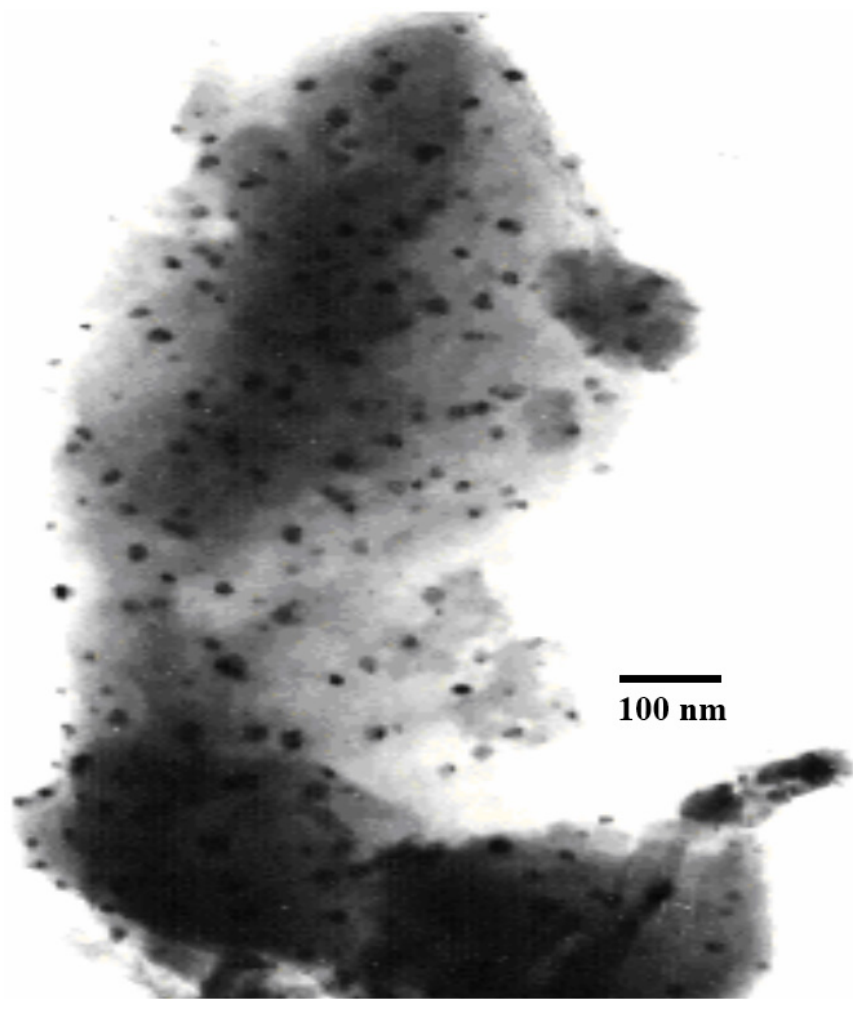

Fig. (9). TEM image of $\mathrm{Ni}-\mathrm{Ca} / \mathrm{AC}$ after $90 \mathrm{~min}$ reaction at $650^{\circ} \mathrm{C}$.

\subsection{Summary and General Discussion}

A summary of the above discussion can be pointed out. In agreement with the proposed mechanism of Baker et al. [26] the nickel nanoparticles are trapped (Fig. 8) because the carbon nanotubes are growing from the particle acting as catalyst. After growth, MW-CNT can be destroyed by the applied experimental conditions, and mixtures of nickel nanoparticles plus carbon are obtained (Figs. 9, 10). Eventually, this carbon deposits would be in situ activated by $\mathrm{CO}_{2}$, with the concomitantly increase in surface area (Table 1). Rigorous kinetic studies of activity of Ni-based catalysts in the methane reforming and their selectivity to carbon deposits, hydrogen and syngas have been reported using electrobalance [27] and thermobalance [28]. The results obtained in the present work are in agreement with these studies because in the experimental conditions of the present work $\left(650^{\circ} \mathrm{C}, 1 \mathrm{~atm}\right)$ carbon dioxide is able to react with the carbon deposits formed by the methane cracking reaction. In addition, strong Lewis bases as $\mathrm{CaO}$ or $\mathrm{CaCO}_{3}$ not only can play a promoter role as have been early reported [1-4] but also clearly influence the balance of reactions involved during dry methane reforming [28] or steam/dry methane reforming [27] and therefore, the selectivity to coke and hydrogen. Therefore, present enforces are aimed to verify the influence of physicochemical properties of activated carbon and different types of promoters on changes in activity, selectivity and stability of Ni-based catalysts during dry reforming and catalytic cracking of methane. 

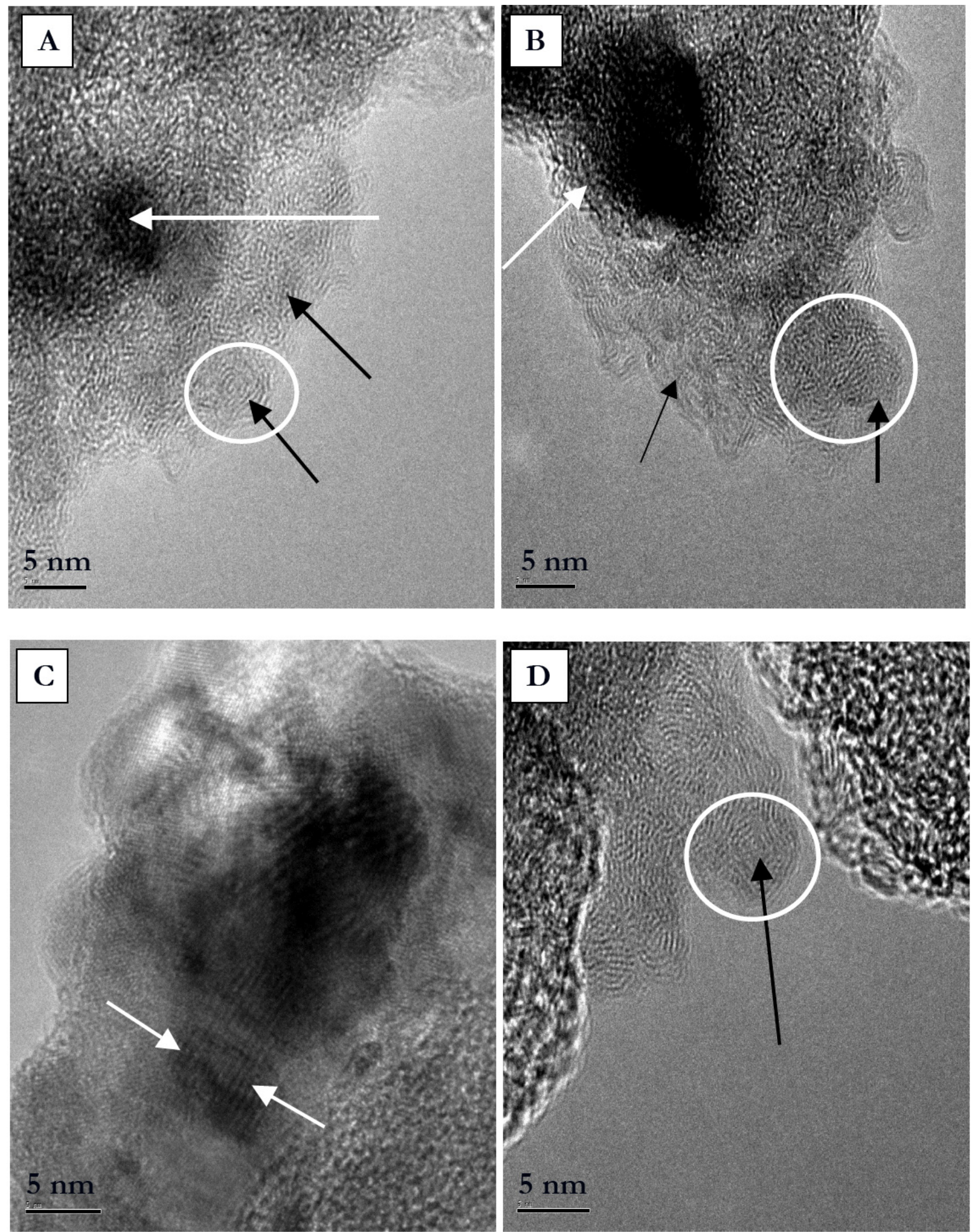

Fig. (10). HR-TEM image of Ni-Ca/AC after 90 min reaction at $650^{\circ} \mathrm{C}$. (A) and (B): Nickel nanoparticles (white arrows). (C): Diffusion of crystallites through several very-well aligned (white arrow) carbon layers. (D): Apparent morphology of carbon nano-onions (white circle). 


\section{CONCLUSIONS}

Changes in textural properties and morphology of Ni$\mathrm{Ca} / \mathrm{AC}$ catalyst were verified during dry methane reforming. An increase in one order magnitude in surface area was detected and it was attributed to in situ activation by gasification with $\mathrm{CO}_{2}$ of carbon deposits formed during reaction. HR-TEM showed diffusion of Ni nanoparticles and carbon-like nano-onions with a separation of graphene layers about $0.5 \mathrm{~nm}$ which is consistent with the formation of a supermicroporous carbon structure. The present results suggest that introducing $\mathrm{CO}_{2}$ pulses during reactions, carbon-supported $\mathrm{Ni}-\mathrm{Ca}$ could be employed as potential catalysts for methane and other hydrocarbon reforming reactions. Our present enforces are aimed to the study of oxidation of light hydrocarbons such as ethane, propane and so on, and small organic molecules like alcohols under mild experimental conditions, mainly at low temperature and atmospheric pressure.

\section{ACKNOWLEDGEMENTS}

J. Matos thanks to Electron Microscopy Centre of Venezuelan Central University and to University of Texas for TEM and HR-TEM studies.

\section{REFERENCES}

[1] Tomishige K. Syngas production from methane reforming with $\mathrm{CO}_{2} / \mathrm{H}_{2} \mathrm{O}$ and $\mathrm{O}_{2}$ over $\mathrm{NiO}-\mathrm{MgO}$ solid solution catalyst in fluidized bed reactors. Catal Today 2004; 89: 405-18.

[2] Bradford MCJ, Vannice MA. $\mathrm{CO}_{2}$ reforming of $\mathrm{CH}_{4}$. Catal Rev Sci Engin 1999; 41: 1-42.

[3] Bradford MCJ, Vannice MA. Catalytic reforming of methane with carbon dioxide over nickel catalysts. Catalyst characterization and activity. Appl Catal A Gen 1996; 142: 73-96.

[4] Rostrup-Nielsen JR, Hansen JHB. $\mathrm{CO}_{2}$ reforming of methane over transition metals. J Catal 1993; 144: 38-49.

[5] Slagterm A, Schuurman A, Leclercq C, et al. Specific features concerning the mechanism of methane reforming by carbon dioxide over $\mathrm{Ni} / \mathrm{La}_{2} \mathrm{O}_{3}$ catalyst. J Catal 1997; 172: 118-26.

[6] Frusteri F, Spadaro L, Arena F, et al. TEM evidence for factors affecting the genesis of carbon species on bare and K-promoted $\mathrm{Ni} / \mathrm{MgO}$ catalysts during the dry reforming of methane. Carbon 2002; 40: 1063-70.

[7] Bai Z, Chen H, Li B, et al. Methane decomposition over Ni loaded activated carbon for hydrogen production and the formation of filamentous carbon. Inter J Hydrogen Energy 2007; 32: 32-7.

[8] Matos J, Brito JL, Laine J. Activated carbon supported Ni-Mo: Effects of pretreatments and composition on catalyst reducibility and on ethylene conversion. Appl Catal A Gen 1997; 152: 27-42.

[9] Matos J, Laine J. Ethylene conversion on activated carbon supported NiMo catalysts: Effect of the support. Appl Catal A Gen 2003; 241: 25-38.

[10] Matos J, Díaz K, García V, et al. Methane transformation in presence of carbon dioxide on activated carbon supported nickelcalcium catalysts. Catal Lett 2006; 109: 163-9.
[11] Díaz K, García V, Matos J. Activated carbon supported Ni-Ca: Influence of reaction parameters on activity and stability of catalyst on methane reformation. Fuel 2007; 86: 1337-44.

[12] Li Y, Zhang B, Xie X, et al. Novel Ni catalysts for methane decomposition to hydrogen and carbon nanofibers. J Catal 2006; 238: 412-24.

[13] Li Y, Chen J, Chang L, et al. The doping effect of copper on the catalytic growth of carbon fibers from methane over a $\mathrm{Ni} / \mathrm{Al}_{2} \mathrm{O}_{3}$ catalyst prepared from Feitknecht compound precursor. J Catal 1998; 178: 76-83.

[14] Harkins WD, Jura G. Surfaces of solids. XIII. A vapor adsorption method for the determination of the area of a solid without the assumption of a molecular area, and the areas occupied by Nitrogen and other molecules on the surface of a solid. J Am Chem Soc 1944; 66: 1366-73.

[15] Labib ME, Williams R. The use of zeta-potential measurements in organic solvents to determine the donor-acceptor properties of solid surfaces. J Colloids Interface Sci 1984; 97: 356-66.

[16] Kroll VCH, Delichure P, Mirodatos C. Methane reforming reaction with carbon dioxide over a $\mathrm{Ni} / \mathrm{SiO}_{2}$ catalyst: The nature of the active phase. Kinet Catal 1996; 37: 698-705.

[17] Resasco DE. Single Walled Carbon Nanotubes. Large-scale production and commercial applications. J Nanopart Res 2002; 4: $131-6$.

[18] Wigmans T. Industrial aspects of production and use of activated carbons. Carbon 1989; 27: 13-22.

[19] Matos J, Labady M, Albornoz A, et al. Topological organization and textural changes of carbon macro-networks submitted to activation with $\mathrm{N}_{2}$ and $\mathrm{CO}_{2}$. J Mater Sci 2004; 39: 3705-16.

[20] Song Q, Xiao R, Li Y, et al. Catalytic carbon dioxide reforming of methane to synthesis gas over activated carbon catalyst. Ind Eng Chem Res 2008; 47: 4349-57.

[21] Ramirez S, Ferreira D, Gottberg V, et al. Adding a micropore framework to a parent activated carbon by carbon deposition from methane or ethylene. Carbon 2003; 41: 2653-5.

[22] Albornoz A, Labady M, López M, et al. Evidence for the formation of slit mesopores in activated carbon. J Mater Sci Lett 2000; 18: 1999-2000.

[23] Krasil'nikova OK, Voloshchuk AM, Evsyukhin AE, et al. Preparation of ultramicro-, micro-, and supermicroporous carbon adsorbents by template procedure. Colloid J 2006; 68: 182-8.

[24] Méndez MOA, Lisbôa ACL, Coutinho AR, et al. Activated petroleum coke for natural gas storage. J Braz Chem Soc 2006; 17: 1144-50.

[25] Imasaka K, Kanatake Y, Ohshiro Y, et al. Production of carbon nanoonions and nanotubes using an intermittent arc discharge in water. Thin Solid Films 2006; 506-7: 250-4.

[26] Baker RTK, Barber MA, Harris PS, et al. Nucleation and growth of carbon deposits from the nickel catalyzed decomposition of acetylene. J Catal 1972; 26: 51-62.

[27] Snoeck JW, Froment GF, Fowles M. Steam $/ \mathrm{CO}_{2}$ reforming of methane. Carbon Filament formation by the Boudouard reaction and gasification by $\mathrm{CO}_{2}$, by $\mathrm{H}_{2}$, and by steam. Ind Eng Chem Res 2002; 41: 4252-65.

[28] Gronchi P, Fumagalli D, Del Rosso R, et al. Carbon deposition in methane reforming with carbón dioxide. J Thermal Anal Calor 1996; 47: 227-34. 